\title{
Baudrillard Bağlamında Hiper-Gerçeklik Kuramının Futbol İzleyicileri Üzerine Etkisi
}

\author{
DOI: $10.26466 /$ opus.661678
}

*

\author{
Barıș Sentuna * \\ * Dr. Öğr. Üyesi, Balıkesir Üniversitesi, Fen-Edebiyat Fakültesi, Sosyoloji Bölümü, Balıkesir /Türkiye \\ E-Posta: ejderkelebek@gmail.com \\ ORCID: $\underline{0000-0001-9982-8382}$
}

\section{Öz}

Bu makalenin amacı, öncelikle futbol izleyicilerinin statta futbol izlemek yerine televizyonları başında hiper-gerçek bir izleme deneyimi yaşamalarının sebeplerini araştırmak ve futbol izlemenin hiper-gerçek boyutunu hem kendi deneyimlerime dayanarak Balıkesirspor hem de Baudrillard üzerinden anlatarak futbol izleyicileri üzerindeki etkilerini tartışmaktır. Bu makale iki ana bölümden oluşmaktadır. Birinci bölümde, futbol izleyicilerinin hiper-gerçekliği tercih etmelerinin sebepleri incelenmiştir. Bu incelemenin sonucunda dört madde öne çıkmıştır. Güvenlik,spiker, değiş̧en gerçeğin heyecan verici yönü ve tekrar oynatmadır.Bunlar sırasıyla incelenmiş ve karşıt görüşü olarak stadyumdaki birliktelik ile beraber tartışılmışıır. Bu makalenin ikinci bölümünün ilk kısmında Platon ve Baudrillard arasındaki benzerlikler ile gerçeklik ve simülasyon kuramı tartışılmaktadır. Ikinci kısımda ise, futbol izleyicilerinin hiper gerçekliğe geçişi bölümünde, hiper-gerçekliğin büyülü dünyası tartışılmaktadır. Hiper-gerçekliğin etkisi bölümünde ise simülasyonun ortaya çıkarmak istediği şeyin, yani -mış gibi hissetmek duygusunun nasıl ortaya çıktığı aktarılır. İzleyiciler artık gerçek ile gerçek olmayanı ayırmamaktadırlar. Çünkü gerçeklik kalmamıştır, yeniden üretilmiştir. Sonuç bölümünde ise futbolun endüstriyelleşmeye, izleyicilerinin ise tüketicilere nasıl dönüştükleri tartışılmıştır.

Anahtar Kelimeler: $\quad$ Spor Sosyolojisi, Futbol İzleyicileri, Baudrillard, Hiper-gerçeklik, Simülasyon 


\title{
The Effects of Theory of Hyper-Reality on Football Viewers in the Context of Baudrillard
}

\begin{abstract}
The main aims of this article is to explore why football viewers choose to watch football on TV, as a Baudrillardian hyper-reality experience, instead of watching it at stadium and to discuss the hyperreality aspect of watching football both from a Baudrillardian perspective and based on my own experience over Balikesirspor. The article is based on two main parts. In the first part, the reasons why football viewers prefer hyper-reality experience are discussed. This examination revealed four items. Security, commentator, the excitement of changing reality and replay. These are examined respectively and as a counter-argument discussed with the unity in the stadium. In the second part, which has two subsections, firstly the similarities between Platon and Baudrillard are discussed in regards to the concepts of reality and simulation. Secondly, in the subsection of the transition of football viewers into hyper-reality, the magical world of hyper-reality is discussed. In the subsection regarding the effects of hyper-reality, how simulation tries to create the feeling of "as if" in us is explained. The viewers cannot differentiate between what is real and what is not real. Because there is no reality left, it is reproduced. Finally, in the conclusion, the processes of how football turns into a sector and how its viewers are transformed into consumers are discussed.
\end{abstract}

Keywords: Sociology of Sports, Football Viewers, Baudrillard, Hyper-reality, Simulation 


\section{Giriş}

Çocukluğumdan beri memleketim Balıkesir'in bir futbol taraftarıyım. Uzun yıllar boyunca taraftarlı̆̆ım değişmedi. Fakat bu uzun yıllarda birçok şey değişti. Bu makale boyunca bu değişiklikleri ve sporun geleceğini hem kendi deneyimlerime hem de felsefi görüşlere dayalı farklı perspektiflerden incelemeye çalışacağım. Bütün bunları yapmaya yine Balıkesirspor ile başlayacağım.

Balıkesirspor futbol takımı 2014'te bir rekor kırd1. 2.lig ve 1. ligte art arda şampiyon olup süper lige çıtı. 2.ligten itibaren hemen hemen tüm iç saha karşılaşmalarına gittim. Liglerin yükselmesiyle birlikte hızla değişen pek çok şey deneyimledim. Balıkesirspor; Fenerbahçe, Galatasaray, Beşiktaş gibi büyük takımlarla oynamaya başladı. Önce stada büyük elektronik bilboardlar geldi. Stadyumdaki büyük TV kuleleri, canlı yayın için hazırlandı. Kendimi bildiğimden beri orada olan stadyum gece maçları için büyük ve uzun kulelerle aydınlandı. Memleketimde bir gece maçına gitmek benim için tamamen farklı bir deneyim oldu.

UEFA kupası sahibi Galatasaray ile gösterişli ışıklarla aydınlatılmış bir gecede büyük bir maç yaptık. ("Balıkesirspor 2-0 Galatasaray", 2014) Galatasaray'ın bütçesi Balıkesirspor'dan çok daha büyüktü. Mucize oldu ve Balıkesirspor maçı 2-0 kazandı. Stadyum hıncahınç doluydu. Ben golleri zar zor görüyordum, nasıl bir oyun oynadığımızı kalabalık ve gürültüden tam olarak kestirememiştim. Eve döndügümde, bizim için bu muazzam galibiyetin görkemini yeniden izlemek için TV'yi aç九ım. Bu noktada bir şeyler fark etmeye başladım. Büyük ekranlı televizyonun önünde izlediğim şey, deneyimlediğim "gerçeklik", birkaç saat önce statta izlediğimden çok daha çekiciydi. Halen daha Balıkesirspor'un maçlarını izliyorum fakat artık televizyondan izlemeyi tercih ediyorum. Bu da aslında Baudrillard'ın tarif ettiği hiper-gerçekliğin bir örneği gibiydi. O zaman hiper-gerçekliğin futbolla nasıl ilişkilendirileceğine göz atalım.

\section{Futbol izlemenin hiper-gerçek boyutu}

Futbol izleyicileri için yeni hiper-gerçeklik deneyimini ve sahada futbol izlemek yerine televizyon karşısında futbol izlememizin sebeplerini madde madde anlatmaya çalışacağım. Bu akıl yürütme daha önce yapılmadığından 
ve bu konuda kaynak olmadığından, kendi deneyimlerim üzerinden bunun sebeplerini kurgulamaya çalışacağım ve tartışmamı bu şekilde kuracağım.

Televizyonda futbol izlemeyi tercih etmemizin sebeplerini düşünürken, aklımıza gelebilecek ilk sebep güvenliktir. En basit haliyle hayatta her şeyden önce güvenlik gelir. 2016 yılında Beşiktaş stadında on iki polis memuru terör saldırısında 36'sı emniyet mensubu, 8'i sivil en az 44 kişi şehit oldu (NTV, 12.12.2016). 2017 yılında, Dortmund otobüsüne saldırı düzenlendi (AA, 27.11.2018). Bundan önceki 132 kişinin öldüğ̈̈ 2015 Paris saldırılarında ana hedeflerden bir tanesi bir stadyumdu. Bir diğeri ise stadyumun dışındaki restorand1. "Reuters'a konuşan bir görgü tanığı, intihar saldırllarından birinin, stadyumun hemen dışındaki bir fast food restoranının önünde gerçekleştiğini söyledi. Bu saldırılarda en az beş kişinin öldüğ̈̈̈ bildirildi." (Hürriyet,3.11.2015).

Kitlelere yapılan bu korkunç terör saldırıları, bizi kalabalık yerlerden uzak tutma amacını taşımaktaydı. Her ne kadar başarılı olamasalar da, insanlar maçın atmosferini statta deneyimlemek yerine, evlerindeki televizyondan izlemeyi yeğler hale geldiler. Çünkü evde tamamen güvende olduklarını düşünüyorlardı. Güvenlik bir sorundur tabi ki; ancak maç deneyimini değiştirmenin yegâne ölçüsü değildir. Evde maç izlemeyi seçmenin birkaç nedeni vardır. Onları analiz etmeye devam edeceğim.

Evde maç izlemeyi tercih etmenin ikinci sebebi, stadyumda spikerin olmamasıdır. Özellikle süper lig altı iki takım oynarken karşı takımın oyuncularının ismini bilmek zordur. Oyuncunun özellikleri, hatta oyuncunun kişisel geçmişi TV ekranında sunulmaktadır. Televizyonda duyduğunuz şey, yalnızca seyircilerin tezahürahatları veya spikerin yorumları değil; aynı zamanda seyircinin pozisyonlara olan tepkisidir. Birkaç yıl önce bir yayıncı kuruluş, televizyon izleyicisine sunucu seçme şansı tanıdı. Siz hayranı olduğunuz veya tarafsız bir anlatıcı seçebilirdiniz. Ancak izleyici, seçim sistemi fikrinden hoşlanmadı. Bu, sadece tarafsız sunucu meselesi değildi. Aynı zamanda yayın şirketleri hiper-gerçeklik sistemine birçok şeyi ekleyebilir veya sistemi alt üst edebilirdi. Çünkü izleyici, kendi izlediğini zaten tarafsız bir gerçek olarak kabul ediyordu. Taraflı bir anlatımı, gerçeğin çarpıtılması biçiminde yorumladı. Bu aslında traji-komik bir durum olarak karşımıza çıkmaktadır. Bu durum televizyonun, beyaz camın yansıttığını, "objektif bir gerçeklik olarak kabul ediyoruz" anlamına gelmektedir. 
Televizyondan maç seyretmeyi tercih etmenin diğer bir sebebi, değişen gerçeğin heyecan verici yönüdür. Bu tür gerçeklikte her şey çok açıktır. Stadyumunuzdaki yerinize göre paranız ve biletiniz doğrultusunda oturup bazı pozisyonları görebilir ve başka pozisyonlar göremezsiniz. Stadyumda biri önünüzde yükselir. Özellikle gol anında büyük kargaşa olur, bazen sadece seslerden gol olduğunu anlarsınız. Ne yazık ki yalnızca bizim gibi izleyiciler değil, sahadaki hakem bile pozisyonu göremeyebilir. Bu nedenle FIFA, video yardımcı hakeme (VAR) geçmeye başladı. Böylece kaydedilen ve değiştirilebilme olasılığı olan gerçeklik, oyunun kendisini etkilemeye başladı.

En başından kendisi hiper-gerçekliğin nesnesi olan televizyon ekranı bizzat futbol sahasına indi. Hakem VAR sistemine başvurduğunu göstermek için televizyonu eliyle gösterir gibi dikdörtgen bir işaret yapıp, gerektiğinde VAR odasında danışır, gerektiğinde bizzat kendisi sahada bulunan televizyondan pozisyonu izler ve buna göre karar verir oldu. Oysaki televizyonun başında maçı canlı takip eden izleyiciler hakem izlemeden pozisyonların tekrarlarını ofsayt ya da el olduğunun yakın çekimlerini çoktan izliyorlardı. Bu anlamda VAR ile birlikte futbol oyununun kendisi bir hiper-gerçekliğin konusu olmaya başladı. Çekilen çizginin "gerçekliği" bir tartışma konusu, "kameranın açısı" başka bir tartışma konusu olmaya başladı. Televizyonlarda saatlerce bitmiş maçları konuşan eski hakemlerin oluşturduğu pazar bu anlamda yerini sahaya uyan televizyondan, televizyona uyan sahaya birakmaya, bu da beraberinde hiper-gerçeklik anlamında büyük paralar kazanan yayıncı kuruluşların, dolaylı bir müdahalesi gibi görülebilecek yepyeni bir modele kendini biraktı.

Televizyon başında futbol izlememizi sağlayan sebeplerin dördüncüsü, tekrar oynatma fonksiyonudur. Üniversitedeyken aylarca stadyuma gidemediğim dönemler oldu. Tekrar stada gittiğimde fark ettiğim ilk şey; televizyondaki tekrar oynatma özelliğinin eksikliğiydi. Stadyumda her şey çok hızlı gerçekleşiyordu. Maçı beraber izlediğim arkadaşıma, "Ne düşünüyorsun; ofsayt mıydı?" diye sorardım. Çünkü çoğunlukla pozisyonu göremezdik. Elbette ki stadyumda bulunduğumuz açı da önemlidir, zira televizyon kutusunun önündeki açı her zaman mükemmeldir. Televizyonda yayınlanan herhangi bir maçta sahayı izleyen yaklaşı 16 veya daha fazla kamera var (TFF, Var Broşürü). Çizgi kamerası, gol kamerası, ofsayt kamerası gibi yeni teknolojiler de var. 
Spor taraftarları olarak maçı çoğunlukla canlı olarak izliyoruz. Ancak yeni dünyadaki bu "canlı etkinlik" görecelidir. Oynatma her zaman bir kayıt ile birlikte gelir. Özellikle önemli pozisyonları ağır çekimde yakalamak muhteşem bir özellik olarak karşımıza çıkıyor. Aylar önce eş zamanlı olarak olarak Türk klasikleri arasındaki Fenerbahçe ve Galatasaray ile El-Classico Barcelona ve Real Madrid arasındaki maçlar vard. Hipergerçeklik kutusu olan televizyon başka bir şey izlerken bile "kayıt" özelliğine sahiptir. Yeni dünyada "sanki canlıymış gibi" izleyebilme şansına sahipsiniz. Eğer maçın sonucunu hiçbir yerden duymadıysanız, sonradan izlediğinizde sanki canlıymış, o anda oynanıyormuş gibi algılamanız mümkündür.

Tabi ki, felsefi bakış açısında her görüşün karşıt bir fikri vardır ve de olmalıdır. Futbol izleyicilerinin hipergerçekliği tercih etmelerinin karşıt fikrinin ne olduğu bizim için önemlidir. Karşıt fikir olarak, televizyon önünde gerçekleşen izleyiciliğin yerine, stadyumda binlerce insanla birlikte sevinç ve hüzün yaşamak, sosyal bir bağı da beraberinde getirir. Böylece siz, aynı duyguları paylaşttğınız bir topluluğun parçası olursunuz. Bu da beraberinde bir aidiyeti getirir. Evde maç izlemeyle karşılaştırdığınızda statta kendinizi daha aktif hissedebilirsiniz. Fakat unutmamamız gereken şey, ilerleyen zamanlarda teknolojinin bunları harmanlayabilecek olmasıdır. Yani insanlar izledikleri maçı yakın bir gelecekte, statlardan seçtikleri koltuklarda, arkadaşları ile VR (Sanal Gerçeklik) üzerinden konuşarak izleyebilir. Hatta maçın hemen ardından maçı konsollarından kendi aralarında oynayabilir ve arkadaşları ile paylaşabilir hale gelecekler. Yukarıda bahsettiğimiz unsurlar sebebiyle futbol izleyicisi için hiper-gerçeklik yakın zamanda tüketimine parelel olarak yepyeni teknolojileri de beraberinde getirecektir.

\section{Platon ve Baudrillard}

İzleyicinin televizyon karşısında gerçeklik yerine imgeleri izlemesi, Baudrillard bağlamında, Platon'un mağara alegorisine dayanan bir fikirdir. $\mathrm{O}$, mağara alegorisini kullanarak gerçekliğin doğası hakkındaki felsefi soruların bazılarını cevaplamaya çalıştı. İlk olarak Platon'un mağara alegorisinden yola çıkacak olursak, Platon'a göre mağaradaki insanlar sadece durdukları yerde kafaları nereye doğru bakıyorsa o açıdan gördüklerini izlerler, işitirler ve öyle kabul ederler. İçlerinden birkaçı fark ederse sadece tek bir yöne değil; etrafına da bakar. Baktığında fark ettiği şey ise ilk başta baktığı yöndeki görüntünün 
gerçek olmadığı, aslında bu görüntünün mağarada yakılan ateşin etrafından geçenlerin birer yansıması olduğudur. Böylece, ilk başta gördükleri görüntünün birer yansımadan ibaret olduğunu anlarlar. Önce, sürekli bulundukları mekânın gerçekliğini kabul ederler. Mekân değiştirdiklerinde ise, o ortamda gerçek olarak izlemledikleri şeylerin aynı etkisi altında değillerdir. Güneşle birlikte aslında, gerçeği görmelerini sağlayan şeyin güneş olduğunu fark ederler. (Platon, 1937, 514-a-c).

Günümüz ile ilişkilendirecek olursak; dünyada mevcut olan çoğu şeyin aslının değil de gösterilmek istendiği şekilde sergilendiğini ve bizim onu o haliyle kabul ettiğimiz söylenebilir. Sahip olunmayan şeye sahipmiş gibi davranma, bize sunulan anların sunulduğu şekliyle ve semptomlarıyla birlikte yaşama, yani göstergeleri konulmuş bir gerçek gibi algılama, bu duruma örnek olarak verilebilir. Bunu tam anlamıla J.Baudrillard'ın hiper-gerçeklik kavramıyla özdeşleştirebiliriz. Bu kavramı daha iyi anlamak için Baudrillard'ın yazdığı çeşitli yerlere göz atalım.

Baudrillard'a göre; "sıradanlaşan mekânlara kozmik değer yüklenip bu mekânlar dünyaya ait değil de, uzayda yüceltilen yerler olarak görülmemiz sağlanır. Bu, bilimkurgu da dahil olmak üzere metafiziğin sonudur. Çağımızın yeni adı hipergerçekliktir." (Baudrillard, 2003, s.172).

"Yeni dünyamızda gerçek kavramı artık düşsellikle arasını iyice bozacaktır. Minyatürleştirmenin genetiği simülasyona özgüdür ve gerçek, günümüzde bununla sonsuz kere üretilmektedir. Rasyonel olana insanın ihtiyacı kalmamıştır. Artık işlemsel bir gerçek vardır. Fakat düşsel olanın yitimi, gerçeğin de yitimi demektir aslında. Anlatılan hiper-gerçeklĭgin ta kendisidir. Gerçek ya da hakikate özgü perspektifle bir ilişkimizin kalmadığııı gösteren bu farklı bir uzama geçiş olayıyla birlikte, tüm gönderen sistemlerinin tasfiye edildiği bir simülasyon çă̆ına girilmiştir. Bu, özünde bir taklit değildir. Gerçek yerine yansitılan, göstergelerden oluşturulmuş bir durumdur. Asıl gerçekten bir vazgeçme olayıdır." (Baudrillard, 2003, 14-15)

Bu yaklaşım, Baudrillard'ın düşüncelerinin önemli bir kısmını barındırır. Artık kavramların içi boşaltılmış, nesnelerin üzerine birtakım anlamlar yüklenmiştir. Gerçek asla bir daha geri dönmeyecektir. Hiper-gerçeklikte tekrar yoktur. Fakat çağrışımsal anlamlarının çok fazla olduğunu birçok örnekte görebiliriz. 


\section{Futbol İzleyicilerinin Hiper-gerçekliğe Geçişi}

Tekrar maç konusuna dönecek olursak; televizyondan maç izleyen seyirci, stada gitmemeyi seçerek, aslında gerçekten vazgeçmiş olmaktadır. Futbol izleyicilerinin kurgusal bağlamda bir ideolojik tezgâh içerisinde olduğunu, sürekli semptomların bir anlam kavramsallaştırmasına bağlandığını görebiliriz. Baudrillard burada artık gerçekliğin bir temsilin ötesine geçtiğini anlatmaktadır. Futbol izleyicilerinin stadyumda maçı seyrederkenki hissettiği duyguların ne kadarı onlara ait, ne kadarı biçimlendirilmiş? Futbol maçı süresince içinde bulundukları etki düzeyleri neye göre şekilleniyor? Bunlar temel sorular haline gelmiştir.

Bir anındalık yaratılmaktadır aslında. Futbol izleyicilerine doğrudan katılım izlenimi verilmektedir. Sunulan bu hiper-gerçeklikle anlamlar artık göstergelere indirgenmiş, asıl anlam bozulmuş, yok olmuş ve değiştirilmiştir. Gerçek, artık tüm göstergelerine sahip gerçek olmayandır. Futbol taraftarı olmak bile içerisinde belirli birtakım imge bombardımanlarını oluşturmaktadır. Gerçek ile sahte arasındaki fark yok edilmeye çalışılır.

Futbol izleyicileri stadyumda maçı sadece bulundukları konuma göre görebilmektedirler. Yani maçı her açıdan görebilme imkanları yoktur. Kişiler, stadyumda maça birebir tanıklık etmekle birlikte duyguları, düşünceleri yani genel tutum ve tavırları bakımından gerçekten kendi duygu tutumlarını mı sergilemektedirler yoksa bir taraftar ve izleyici olarak onlara önceden belirli davranış kalıpları mı oluşturulmuştur? Kişilerin birçoğu gerçekten taraftar veya izleyici olduğundan değil; sadece oradaki atmosferin yani maç boyunca süren 'büyülü' dünyanın peşinden koşmaktadırlar. Çünkü reklamlar, maçbiletleri ve sunulan görsellerin hepsi bir şey vaat etmektedir. Televizyon ekranlarından izleyenleriyse sanki statta izliyormuş hissine, oradaymış yanılgısına düşürmektedir. Bu his, o kadar dikkat çekmeden verilmektedir ki, kişiler bütün duygularının kendilerine ait olduğu yanılgısına düşmektedir. Futbol maçının devamındaki programlar, bir yenilgi sonrası nasıl düşünülmesi gerektiğini, yenilginin nasıl anlaşılması gerektiğini defalarca, birbirleriyle kavga eden adamlar üzerinden izleyicilere adeta dikte etmektedir.

Artık nesneler, olaylar, gündelik yaşam pratikleri yalnızca bireylerin ihtiyaçlarını karşılamak için değil; bireyleri birtakım ekonomik, siyasal, sosyal sistemler içerisine bir şekilde dahil etmek için kullanılmaktadır. Doğrudan 
işlevleri bu olmuştur. Bireylerin çoğu bunun farkında değildir. Sistem içerisindeki mevcut konumlarl, algıları, gereksinimleri bunlar doğrultusunda şekillenmiştir. Buna verilebilecek en güzel örneklerden bir tanesi, Çin'de futbolun yükselen bir değer olmasıdır. Neredeyse pek çok ünlü futbolcu jübile niteliğinde yaşları ilerlediğinde Çin piyasasına girmektedirler. Yayın gelirleri bunun en belirleyici unsurudur. Çin'in yayın gelirleri, nüfusu gereği astronomik rakamlara ulamıştır. Çin Süper Ligi'nin yayın hakları bugüne kadar satılan en büyük yayın hakları rakamına ulaşmıştır (Financial Times, 2016).

"Futbol asla sadece futbol değildir" (Kuper, 2006) sözünden yola çıktı̆̆ımızda, futbolun futboldan daha gerçek bir konuma, bir hiper-gerçekliğe dönüştügünü söyleyebiliriz. Bir hiper-gerçeklik halini alan evrende nesnelere yüklenen anlamlar medya, reklamlar vb. yoluyla oluşturulmakta ve değiştirilmektedir. Bireyler de bu oluşturulan anlamlar üzerinden kendilerine ait bir alan yaratmaya çalışmaktadırlar. Bu oluşturulan algıları dolayısıyla bireyler; toplumda çeşitli toplumsal statülere ulaşmak, bir gruba ait olmak veya mutlu olmak adına birçoğu kendilerine ait olmayan fikirlerle eylemlerini gerçekleştirmektedirler. Oluşturulan bu toplumsal düzenek, bireylerde o alana dahil olduklarında daha mutlu, daha benimsenmiş ve daha konforlu bir yaşamlarının olacağı yanılgısı yaratır. Fakat o oluşturdukları alanlar gerçekten kendilerine mi aittir ya da benimsedikleri alan içerisinde gördükleri ne kadar gerçektir?

Gerçek artık gerçek olarak inandırılmak istendiği halde tüm göstergelerine sahiptir, fakat gerçek olmayandır. Adeta gerçekmiş gibi bir sunum yapılmaktadır. Bir şeyleri gizleyen göstergeler aşamasından, gösterilecek bir şey kalmadığını gizleyen göstergeler aşamasına geçiş bir dönüm noktasıdır (Baudrillard, 2003, s.21).

Futbolun etkisi; sahadan çıkıp televizyonlara, internete, gazetelere, telefonlara, bütün sosyal medyaya ve sokaklara kadar yayılmıştır. Futbol izleyicileri, etkisinden çıkamadıkları edimlerini sadece maç boyunca değil; daha sonra da devam ettirmektedirler. Maç esnasında olanları benimseyip daha sonra bunu maç sonrasına taşımaktadırlar. Stadyumu terk edene kadar, karşı takımın taraftarlarıyla birbirlerine düşmanmış gibi davrandıkları görülür. Futbolun doğasının kazanma, rekabet vs. olduğuna inanırlar ve maç esnasında kendilerini o kadar kaptırırlar ki bu büyülü dönencede asıllarının ne olduğunu unuturlar. 


\section{Hiper-gerçekliğin Futbol İzleyicileri Üzerindeki Etkisi}

Hiper-gerçekliğin süregeldiği bu dünya; kişilerden, taraftarlardan sadece stadyuma gelmelerini beklemez. Futbol oyuncularnyla özdeşlik kurmaların, maç sırasında kendilerini çok iyi hissetmelerini ve bu büyülü yanılgının maç sonrasında da devam etmesini ister. İzleyiciler maç seyrederken keyif almalıdırlar ki bu büyülü dünyayı hep seyretsinler. En önemli noktalarından biri de kendileriyle özdeşlik kurmalarıdır. İzleyicileri stadyumda sanki kendileri oynuyormuş gibi hissettirmesi, hiper-gerçekliği oluşturan özelliklerdendir. Talimciler' in Girtler'den aktardığı şekliyle, bu durum şöyle ifade edilir: “Takımınızın taraftarlarının stadyumu doldurması yeterli değildir; sizin kendinizi kıyaslayabilmeniz, takımınızı ne kadar sevdiğinizi gösterebilmeniz için bir ayna benliğe yani rakip takım taraftarlarına ihtiyaç vardır." (Talimciler, 2014).

Simülasyonda "-mış gibi" hissi vardır. Olayları, durumları, görünen her şeyi doğası itibariyle bu şekilde sunar. Göstergeler ve imgeler itibariyle sunmak istediği her şeyi sunar. Aynı şekilde futbol izleyicileri stadyumda kameralar karşısında veya toplu bir şekilde bir yerde maçı seyrederken de dış bir göz tarafından seyredildiğinin farkına vardığı için ya da farkında olduğu için gösterdiği edimler bağlamında büyük oranda doğal olmayacaktır. Öte yandan pek çok davranışı evinde televizyon karşısında da, stadda da gösterebilir ki bu davranışlardan bazıları onun -mış gibi davranışını pekiştiren unsurlar olacaktır. Örneğin rakibe ya da hakeme kötü tezahürat, bunlar taraftarın sosyal kimliğinin dişavurumu olarak gözükebilir. Öte yandan sadece stadda gerçekleşebilecek davranış türleri de vardır. Siyasal sloganlar, yöneticiye ya da federasyona karşı tepkiler de bunlara örnek olarak verilebilir. Evindeki taraftar çok daha ehlidir. Olay çıartması, toplumsal kontrolsüzlük yaratması beklenmez. $\mathrm{Bu}$ anlamda kontrol altındadır. Hiper-gerçekliğin mucizevi büyüsü ile kuşatılmıştır.

Stadyumda da televizyon karşısında da simülasyon ayn etkiyi yapar. İstenilen bir dünya sunma ya da o dünyayı kişinin kendisi istiyormuş gibi bir algi oluşturma bağlamında çok etkilidir. İzleyicileri bu süre zarfında eğlendireceğini vaat eder. Hatta bu süre bitiminde de etkisini devam ettirir. Gözlemlenen çıtılar, etkilerin stadyumun dışında da devam ettiğini gösterir. Televizyon karşısında da durum böyledir. Futbol izleyicileri maçı seyrederken kendisini, sunulan şeye o kadar kaptırmıştır ki kendisini adeta sahadaymış 
gibi hisseder. Birebir maça tanıklık etmez fakat maç süresince, hatta daha sonrasında da bizzat stadyumda izlemiş gibi bir hal-tavır takınmaktadır. Ona sunulan büyülü dünyanın etkisine çoktan girmiştir. Televizyon karşısında futbol izleyicilerinin bütün sesiyle sanki hakemin ya da futbol oyuncularının yanındaymış gibi, kendisini duyacakmış gibi sinirlenip etrafa küfür saçmasını da buna örnek olarak gösterebiliriz.

Talimciler' in makalesinde bahsettiği üzere "izleyiciliğe indirgenen taraftarlık için dev ekranlar, günümüzün en yeni sayfasıdır. İnsanlara adeta bir ev konforu sunmaktadır. Taraftarlık artık tanım değiştirmiştir ve oyunun sadece bir parçası olmuştur." (Talimciler, 2014, s.385) Son olarak Dikici ise "evlerimiz, televizyon sebebiyle minyatür stadyumlara dönüşmüş vaziyettedir. Taraftarlar on ikinci adamlar olarak sanal bir şekilde oyunun içine dahil olmuşlardır." (Dikici, 2014) şeklindeki görüşleri ile durumu nitlendirmiştir..

\section{Sonuç}

Simülasyon evreninde oyun sektöre, taraftar da müşteriye dönüşmüştür. Bir algi yaratım süreci mevcuttur. Futbol izleyicileri tam anlamıyla hiper-gerçeklikle baş başadırlar, fakat birçoğu bunun farkında değildir. Onlar tüm bu süreçlerin ve meydana gelen şeylerin tamamen kendilerinin kontrolü altında olduğunu düşünmektedirler. Fakat onlar sadece bu sistemin kullanılan birer parçası halindedirler. Hayatlarında meydana gelen şeyleri normal bir şekilde süregelen bir yaşam olarak algılamaktadırlar. Göstergelerin altında sıkışıp kalmışlardır. Gerçekle gerçek olmayanı ayırt edememektedirler. Zaten tamamen gerçek diye bir şey kalmamıştır artık. Gerçeklik olarak sunulan yeni bir şeyler vardır. Futbolda sunulan şeyler de bunlardan bir tanesidir.

Futbol oyunları, iddia oyunları, takımların renklerine dayalı nesneleştirilmiş ürünler, reklamlar gibi araçlarla futbol kendi doğasını kaybetmiştir. Futbol izleyicileri hiper-gerçekliğe maruz kalmaktadırlar. Asıl yapısı aktarılmamakta; aktarılan bu şey içinde birçok düşsel, imgesel öğeyi barındırmaktadır. Futbol, artık bir gerçeklik olarak yeniden kurgulanmaktadır. Bu hedef doğrultusunda da bütün araçlar tüm donanımlarıyla kullanılmaktadır. Kişiler özellikle de izleyiciler artık birer gelir kaynağıdır. Onlar daha çok izlediklerinde, daha çok ilgi gösterdiklerinde sistem amacına ulaşmaktadır. Gerçeklik yeniden üretilmiştir. Tekrar oynatımlar bunun önemli bir parçasını oluştu- 
rur. Yayıncı kuruluş istediği açıdan istediği pozisyonu istediği şekliyle ve istediği zamanda tekrar oynatır. Çekilen ofsayt çizgisi ile, hakem hatlarıyla en önemlisi de bitmek bilmeyen, içinde eski hakem ve futbolcuların yer aldı̆̆ı, zaman zaman futbolcuların mahremiyetine kadar inen tartışma programları ile gerçeklik izleyiciler için tekrar ve tekrar yeniden üretilir. Hatta tamamen izledikleri, gördükleri şeyler birer hiper-gerçekliktir. Gerçeklikten tamamen uzaklaşmış, gerçek olarak inandırılmak istendiği doğrultuda bütün göstergelere sahip fakat gerçek olmayandır. Gerçekmiş gibi sunulması büyüsünü arttırır.

Bütün görünenler gerçek olarak kabul edilmekte ve bunun gerçek olup olmadığı sorgulanmamaktadır. Çünkü bu sistemin çıktıları kişilerde o kadar içsellemiştir ki kendi bakış açıları doğrultusunda bir şeyler izlediğini ya da istediği şeylerin tamamen kendi isteğiyle oluştuğunu düşünmektedirler. Çıktıları olarak da futbolun niteliğinden ya da meydana geliş amacından daha çok imgeler ve semboller göz önündedir. Göstergeler anlamin yeniden üretilmesine yol açmaktadır.

Günlük yaşamda kişiler birçok uyarıcıya maruz kalırlar. Uyarıcılarda mevcut olan imge ve semboller dolayısıyla pek çok anlamı içinde barındırmaktadır. Simülasyon da bu noktada devreye girmektedir. Çeşitli imgelerle pek çok görüntü elde edilebilmektedir. Artık gerçek dünya ile imgeler ayırt edilememektedir. Yeni bir dünya ve yeni anlamlar üretilmektedir. Yani gerçeklik, yeniden üretilmektedir. Futbolun yapısı ilk şekliyle değil, sunulan imgelerle yapay bir şekilde yeniden üretilmektedir.

Hiper-gerçeklikte ideolojik temeller mevcuttur. Verilmek istenenler, göstergeler yoluyla futbol izleyicilerine sunulmaktadır. Beyaz camın arkasından gösterilen, sunulan her şeye sorgusuz bir şekilde inanma eğilimindeyiz. Maruz kaldığımız görüntülerin gerçek olup olmadığını ya da gerçekleşip gerçekleşmediğini sorgulamamaktayız. Söylem dili de burada harekete geçmektedir. Medyanın dili de burada başat noktadadır. Futbol maçlarının sunumunda da bunu gözlemleyebiliyoruz. Hiper-gerçek evren sunmak istediği şekilde, iletmek istediği mesajlar ve amaçlar doğrultusunda bunu gerçekleştirmektedir ve bunda da başarılıdır. 


\title{
EXTENDED ABSTRACT
}

\section{The Effects of Theory of Hyper-Reality on Football Viewers in the Context of Baudrillard}

\author{
Barış Şentuna \\ Balıkesir University
}

From my childhood I am a fan of my hometown team Balıkesirspor. My fanaticism did not change overall all those years but a lot of things changed around Balıkesirspor. Throughout this article I will try to think about these changes and future of sports, based on my own experiences and philosophers' perspectives as well.

In 2014 Balıkesirspor broke a record and become champion of 2nd league 1st league and to top league named Super League. I went all home matches starting from 2nd league. Balıkesirspor started to play with biggest international clubs such as Galatasaray, Fenerbahçe, Beşiktaş. I went to first night match in my town, which was like a dream. In 2014 we made a match with Galatasaray who won UEFA cup. We beat Galatasaray with 2 goals which I barely see because of crowd. When I returned home I opened TV and rewatch the game. At that point I started to experience something different. The experience I had in front of my big screen is far attractive than the stadium experience. I still watch Balıkesirspor matches but I choose to watch from TV. It is like a description of hyper-reality of Baudrillard which I will try to describe in this article.

I will try to explain reasons for choosing to watch matches from TV instead of watching it in stadium item by item. The first item is security. In simplest form security comes before everything. 44 people died in deadly attack of terrorists in 2016 Beşiktaş, in 2017 Dortmund bus was attacked, and most importantly in 2015 Paris attacks the main target was stadium. This caused people to watch from homes rather than stadiums. Security is a problem but is not solely enough to change the watching experience.

The second reason to watch from home is commentator. In stadium there is no commentator. It is not only you hear the commentator but also the general sound in stadium as if you are in stadium. In past, the broadcasting platform give an option of fan commentator you can choose. But this is not 
liked by watchers because they think that the what he/she watches is objective. This situation tells us that "what we watch in front of television screen" is objective reality as granted.

The third reason I choose to watch from home TV is the exciting side of changing reality. In the place of stadium especially if it is old, you cannot see all positions clearly. In time of a goal someone stands up in front of you and you cannot see. Not only us, even referees cannot see the positions in front of them therefore the system of VAR started in football. This resulted in the recorded reality can affect the game itself. The referee started to listen VAR room, do a TV sign by arms and can go to the TV in the stadium. But before all, the home TV watcher already sees the position by slow-motion and zoom of cameras. This created a new economic broadcasting of old referees arguing positions hours and hours.

From a philosophical point of view every theory has a counter theory. The counter theory of football fans watching matches at home instead of stadium is watching alone or with some friends at home, prevent the social bonding with thousands of people in stadium feeling the same way. The point we should keep in mind is in near future by their VR glasses people will be watching exactly like they are in stadium. From this perspective the hyper-reality will cause a rise in those new technologies soon.

In the part of passing of football watchers to hyper-reality I will consider the thoughts of Baudrillard and adopt them to football viewers. For Baudrillard the new era is the era of hyper-reality (Baudrillard, 2003, p.172). In this new era the concepts contents are emptied. Over some objects new meanings are assigned. The result is the reality will not come back. The viewer chooses not to go to the stadium, gives up from reality. The gap between reality and fake is tried to be destroyed. This works in both ways. The watcher in stadium goes after the magical world and behaves in the patterns taught to him/her. On the other hand, the watcher at home feels as if they are watching in stadium. The programs following the match teach the way to think after a loose. The effect of football goes away from the stadium to televisions, newspapers, mobile phones, social networks and even to streets. The football viewer's behaviors continue after match. The make themselves too much occupied with the opposite team that they forget in real world who they are.

In the part of the effect of hyper-reality on football viewers, I tried to give some results of hyper-reality over football. The viewer's identification with 
players is very important. The viewers. They should feel the joy so that they want to continue to watch. The viewer at home uses strong language against referee, shouts, jumps etc. these acts reinforce the as if effect of hyper-reality. But in reality the viewer at home is under control. He cannot be part of social violent disobedient acts.

In conclusion part, I tried to sum up my thoughts. In world of simulation game changed into economic sector, and fan changed into customer. The football viewers form all perspectives are left with hyper-reality. They cannot differentiate between real and not real because, there is no reality left. By gambling, merchandise products, the different objectification of every product, football lost its nature. It is created as a new reality. By the new images it re-created.

\section{Kaynakça / References}

Baudrıllard, J. (2003). Simülakrlar ve simülasyon. (O. Adanır, Çev.). Ankara: Doğu Batı Yayınları.

Bland, B. (2016, 4 Nisan). Chinese football more than a game. Financial Times. https://macaudailytimes.com.mo/files/pdf2016/FT-2530-2016-04-04.pdf adresinden erişilmiştir.

Dikici, S. (2014). Yakarız bu gezegeni!. İstanbul: Caretta Kitapları.

İstanbul Beşiktaş'ta Vodafone Arena yakınında iki bombalı saldırı. (2016, 12 Aralık). Anadolu Ajansı. https://www.ntv.com.tr/turkiye/istanbul-besiktastavodafone-arena-yakininda-iki-bombali-saldiri,hsgWcdz2R0C0X564FE8aKg adresinden erişilmiştir.

Karadağ C. (2018, Kasım 27). Borussia Dortmund otobüsüne bombalı saldırıya 14 yll hapis. Anadolu Ajansl. https://www.aa.com.tr/tr/dunyadanspor/borussia-dortmund-otobusune-bombali-saldiriya-14-yil-hapis/1323073 adresinden erişilmiştir

Küçük A. N. (2014, 20 Eylül). Balıkesirspor 2-0 Galatasaray. Hürriyet. http://www.hurriyet.com.tr/balikesirspor-2-0-galatasaray-27244279 adresinden erişilmiştir

Küçük R. (2019, 13 Kasım). Paris'i kana bulayan saldırıların 4. yıl dönümü: Saldırıların tanığı, yaşadığı kabusu anlatıyor. Euronews https://tr.euronews.com/2019/11/13/parisi-kana-bulayan-saldirilarin-4-yildonumu-saldirilarin-tanigi-yasadigi-kabusu-anlatiyor adresinden erişilmiştir

Kuper, S. (1996) Futbol asla sadece futbol değildir. (Gürtunca S., Çev.) İstanbul: Sabah Kitapları Yayınları. 
Platon, (1937). Devlet:7. Kitap, (S. Eyüpoğlu Çev.). İstanbul: Remzi Kitapevi, 514-a 516-c.

Roland G. (2006). Terbiyesizlĭgin teorisi (M. Beyaztaş, Çev.). İstanbul: Kale Yayınları.

Şen, H. (2013). Futbolun değişen yapısı üzerine sosyolojik bir analiz. YDÜ Sosyal Bilimler Dergisi, 6(1), 88-106.

Talimciler, A. (2014). Medyanın biçimlendirdiği taraftarlık. Toplum ve Hekim, 29(5), 381-386.

Türkiye Futbol Federasyonu. (2018). Video yardımcı hakem kitapçı̆̆ı. [Broşür] https://www.tff.org/Resources/TFF/Images/MHK/VAR.pdf adresinden erişilmiştir

\section{Kaynakça Bilgisi / Citation Information}

Şentuna, B. (2020). Baudrillard bağlamında hiper-gerçeklik kuramının futbol izleyicileri üzerine etkisi. OPUS-Uluslararası Toplum Araştırmalarn Dergisi, 16(27), 775-790. DOI: 10.26466/opus.661678. 